\title{
Acetone Fraction of Annona squamosa Seed Extract Inhibits Mitochondrial Complex II of Musca domestica Vivek Kempraj ${ }^{1,2 *}$ and Sumangala K Bhat ${ }^{3}$
}

${ }^{1}$ Biowave Resources, 519, 33rd Cross, 9th Main, IV Block, Bangalore-560011, India

${ }^{2}$ Division of Entomology and Nematology, Indian Institute of Horticultural Research, Hesserghatta Lake Post, Bangalore -560011, India

${ }^{3}$ Department of Biotechnology, Acharya Institute of Technology, Bangalore-560011, India

\begin{abstract}
Mitochondrial respiratory complexes in insects are involved in diverse physiological processes including energy production. Specific and potent inhibitors of complex I, III and IV are described and has allowed in determining the importance of these enzymes in the physiological processes. However, there seems a paucity of information regarding potential inhibitors of complex II of insect mitochondria. In this study we demonstrate the toxicity of acetone fraction (ASF) of Annona squamosa seed extract to Musca domestica and its mitochondrial complexes. Effectiveness of ASF as oral bait and contact poison was also evaluated. Inhibition of Complex II in treated flies has been related to its lethargic nature. Energy inhibition study of ASF further confirmed reduction in ATP.
\end{abstract}

Keywords: Housefly; Complex II; Insecticides; Annona; ATP, Mitochondrial

\section{Introduction}

Synthetic insecticides (SI) are widely used for the control of $M$. domestica. Prolonged and continuous use of SI causes occupational hazard, damage to environment and development of resistance in insects. Therefore, there is a need for an alternative and effective insecticide. Several phytochemicals including acetogenins have been proved effective against houseflies [1-4]. Several compounds and extracts derived from plants of the family Annonaceae are known to exhibit toxic effect on a plethora of organisms [1,5-12] however, studies regarding ASF of seeds of A. squamosa seem meagre [13]. M. domestica is an insect closely associated with the lifestyle of human beings [14]. They are prominent vectors of many diseases [15,16] and affect performance of industries leading to heavy financial loss $[17,18]$. Hence, maintaining the premises free from houseflies is critically important. This study has evaluated the chemical composition and toxic effects of the ASF of A. squamosa seeds on M. domestica and the mode of action of the fraction.

\section{Material and Method}

\section{Plant material and extraction}

Seeds of A. squamosa (234.8 g) were collected from ripe fruits between September to January during 2008-09, washed under tap water to remove the pulp and were shade dried at $27 \pm 1^{\circ} \mathrm{C}$ for 15 days. The seeds were then pulverized in an electric blender (powdered seed size range from $0.1-2 \mathrm{~mm}$ ). The dried powder was defatted by extracting in petroleum ether for $48 \mathrm{~h}$. The defatted dried seed powder was then extracted with ethanol $(1: 2.5 \mathrm{w} / \mathrm{v})$ at $27 \pm 1^{\circ} \mathrm{C}$ for $48 \mathrm{~h}$. The crude extract was filtered and concentrated on a water bath at $40^{\circ} \mathrm{C}$ to obtain a brown thick paste $(\sim 5 \mathrm{~g})$. The concentrated crude extract was dissolved in acetone to yield a soluble and an insoluble fraction. Acetone soluble fraction (hereafter referred as ASF), measuring 150 $\mathrm{ml}$ was passed through a membrane filter (Millipore, $0.45 \mu \mathrm{m}$ ) and concentrated to yield a light brown waxy paste $(\sim 2 \mathrm{~g})$ and refrigerated until further use.

\section{Chemical analysis and identification of the components of the active fraction}

Chemical composition of the active fraction (ASF) was analysed using GC-MS (Perkin Elmer Clarus Gold 500) apparatus equipped with a capillary column (SGE-BPX-5) of $30 \mathrm{~m}$ length and $0.25 \mathrm{~mm}$ ID and $0.25 \mathrm{~mm}$ film thickness. Oven temperature was programmed at $40-270^{\circ} \mathrm{C}$. Helium was used as carrier gas at a flow rate of $1 \mathrm{ml} / \mathrm{min}$. Compounds were identified by GC retention time and mass spectrum using NIST library as reference.

\section{Housefly culture}

A wild strain of housefly ( $M$. domestica) was used in the assay. Houseflies were collected from poultry near the premises of the research centre. They were transferred to culturing cages of dimension, $30 \times 60$ $\times 30 \mathrm{~cm}^{3}$ and allowed to acclimatize to laboratory conditions $\left(27 \pm 1^{\circ} \mathrm{C}\right.$, $75 \pm 2 \% \mathrm{RH}$ and $15 \mathrm{~h}$ light and $9 \mathrm{~h}$ dark photoperiod). Autoclaved concoction of wheat flour, yeast pellets and meat (2:1:2 ratio) served as oviposition medium and as food source for larval stages. Adults were fed on sterile sucrose solution $(10 \% \mathrm{w} / \mathrm{v})$ and peptone solution $(10 \% \mathrm{w} / \mathrm{v})$. The pupae formed were collected from culturing cages and transferred to new cages for emergence of adults. The newly emerged (2-day-old) adults were used throughout the study.

\section{Bioassay}

Oral toxicity: Test concentrations ranging from $0.1-5 \mathrm{mg} \mathrm{ml}^{-1}$ were prepared by incorporating appropriate amount of ASF in sucrose solution $(10 \% \mathrm{w} / \mathrm{v})$ with the help of an emulsifier (Triton X-100; $0.01 \%$ $\mathrm{v} / \mathrm{v})$. Test emulsions $(5 \mathrm{ml})$ were socked on sterile filter paper discs (diameter $10 \mathrm{~cm}$; Whattman) using a micropipette and dried at $27 \pm$ $1^{\circ} \mathrm{C}$. This was repeated several times until $5 \mathrm{ml}$ of the emulsion was completely absorbed by the filter paper. The emulsion impregnated filter paper was cut into square pieces of $1 \times 1 \mathrm{~cm}$ dimension (hereafter referred to as "Bait"). Ten baits were distributed throughout the rearing cages containing 30 numbers of 2-day-old houseflies. This was done to negate the possibility of contact toxicity. Cotton pad socked in

*Corresponding author: Vivek Kempraj, Division of Entomology and Nematology, Indian Institute of Horticultural Research, Hesserghatta Lake Post Bangalore-560011, India, Tel: +91-9731372149; Fax: +91-08-26541973; E-mail: vivek.kempraj@gmail.com

Received September 13, 2014; Accepted October 23, 2014; Published October 25,2014

Citation: Kempraj V, Bhat SK (2014) Acetone Fraction of Annona squamosa Seed Extract Inhibits Mitochondrial Complex II of Musca domestica. Nat Prod Chem Res 2: 155. doi:10.4172/2329-6836.1000155

Copyright: ( 2014 Kempraj V, et al. This is an open-access article distributed under the terms of the Creative Commons Attribution License, which permits unrestricted use, distribution, and reproduction in any medium, provided the original author and source are credited. 
water was provided to the houseflies. Bait containing all ingredients excluding ASF served as control. The mortality data was collected after $24 \mathrm{~h}$ exposure period. The tests were conducted in triplicates and the results analysed statistically. The relation between concentration and mortality was analysed using log-concentration probit analysis $\left(\mathrm{LC}_{50}\right)$ software SYSTAT. If mortality exceeds $10 \%$ in the control batch, the whole bioassay was discarded or if below $10 \%$ the results of the treated sample were corrected using Abbott's formula $[19,20]$.

Contact toxicity: Contact toxicity of ASF to 2-day-old adult houseflies was tested with concentration ranging from $0.1-5 \mathrm{mg} \mathrm{ml}$ ${ }^{1}$. Houseflies were anaesthetised with $1 \mathrm{ml}$ of diethyl ether on cotton pads for 20s and placed on plates cooled to $4^{\circ} \mathrm{C}$ to maintain anaesthesia during the application. Thirty adults were used for each concentration tested. Test concentrations of ASF were prepared by adding appropriate amounts into acetone. A micro-syringe was used to apply $0.1 \mu \mathrm{l}$ of the test concentrations onto the thorax of anesthetized houseflies with the help of stereomicroscope $(20 x)$. A separate batch $(n=30)$ treated with $0.1 \mu \mathrm{l}$ of acetone served as control. The control and treated flies were transferred into separate rearing cages for acclimatization. The bioassay was conducted in triplicates. The mortality data collected after $24 \mathrm{~h}$ exposure period was subjected to log-concentration probit analysis software SYSTAT.

\section{Insect mitochondrial preparation}

Four hundred 2-day-old houseflies were refrigerated for $15 \mathrm{~min}$ to stop their activity. The thoraxes were separated from the head and abdomen using a scalpel with the help of a stereomicroscope (20x) under cold conditions. The mitochondrial preparation method by Knecht et al. [21] was followed with slight modifications. One gram of thorax was homogenized with $10 \mathrm{ml}$ of mitochondrial inhibition buffer (MIB) in a pre-cooled homogenizer. The homogenate was centrifuged at $500 \mathrm{~g}$ for $10 \mathrm{~min}$ at $4^{\circ} \mathrm{C}$. The supernatant was taken in sterile tubes and centrifuged at $30,000 \mathrm{~g}$ for $10 \mathrm{~min}$ at $4^{\circ} \mathrm{C}$. The pellets formed were washed thrice, re-centrifuged, weighed and used immediately.

\section{Determination of protein content}

Protein concentration of the mitochondrial suspensions was determined by the method of Lowry, BSA was used as standard [22].

\section{Mitochondrial enzyme inhibition studies}

Succinate dehydrogenase (SDH) (EC number: 1.3.5.1) activity was measured according to Singer [23]. Mitochondria isolated from thoraxes $(0.26 \mathrm{mg})$ were added to a reaction medium containing 20 mM Sodium succinate, $40 \mathrm{mM}$ HEPES ( $\mathrm{pH} 7.5)$ and $1 \%(\mathrm{v} / \mathrm{v})$ Triton $\mathrm{X}-100$. After $1 \mathrm{~min}$, the reaction was initiated by the addition of 10 $\mu \mathrm{L}$ of $0.5 \%(\mathrm{w} / \mathrm{v})$ DCIP and ASF at varying concentration of $0.0-1.0$ $\mu \mathrm{g} \mathrm{ml}^{-1}$. The reaction was followed at $25^{\circ} \mathrm{C}$ in a spectrophotometer at $600 \mathrm{~nm}$. Activity was calculated from the absorbance decrease, using an extinction coefficient for DCIP of $19.1 \mathrm{mM}^{-1} \mathrm{~cm}^{-1}$. Similarly, toxicity of ASF to mitochondrial malate dehydrogenase (MDH) (EC number: 1.1.1.37) was studied. The reaction medium contained $100 \mathrm{mM}$ Tris$\mathrm{HCl}$ ( $\mathrm{pH}$ 7.8), $20 \mathrm{mM} \mathrm{MgCl}, 1 \mathrm{mM}$ EDTA, $0.1 \mathrm{mM} \mathrm{NADH}$ and 0.5 $\mathrm{mM}$ oxaloacetate. The reaction was initiated by the addition of the enzyme source and ASF at varying concentration of $0.0-1.0 \mu \mathrm{g} \mathrm{ml}^{-1}$. The oxidation of NADH was monitored spectrophotometrically at 340 $\mathrm{nm}$. Activity was calculated from the absorbance decrease, using the extinction coefficient of NADH $\left(6.22 \mathrm{mM}^{-1} \mathrm{~cm}^{-1}\right)$. The $\mathrm{IC}_{50}$ values for each enzyme were calculated using the data obtained.

\section{Estimation of total ATP production}

ATP extraction method described by Yang et al. [24] was followed with slight modifications to determine the total ATP production of treated flies. Oral and contact treated houseflies $(n=60)$ were collected at different time intervals $(1,6,8,12$ and $24 \mathrm{~h}$ ) and frozen for $20 \mathrm{~min}$. Whole flies were homogenized in distilled water $(5 \mathrm{ml})$ and boiled for $15 \mathrm{~min}$. The boiled sample was centrifuged at $5000 \mathrm{~g}$ for $10 \mathrm{~min}$. The supernatant was collected and ATP content determined using the method described by Lamprecht and Trautschold [25]. Flies without any treatment were used as control. The experiments were conducted in triplicates.

\section{Statistical analysis of data}

Data in the graphs are result obtained with independent mitochondrial preparations and are presented as means \pm standard errors (S.E.M). The data were subjected to either Student's $t$-test or analysis of variance (ANOVA) with significant differences among means being identified by Duncan's multiple range test. $\mathrm{P}<0.0001$ was adopted as a criterion of significance. The $95 \%$ confidence intervals (CI) of the lethal concentration (LC) at $50 \%$ and inhibitory concentration (IC) at $50 \%$ were analysed.

\section{Results and Discussion}

Results of the toxicity studies using oral and contact formulations of ASF on adult houseflies are shown in Figure 1 and are clear that the toxicity is dose-dependent. The $\mathrm{LC}_{50}$ for oral and contact formulations of ASF were $2.3 \pm 0.8 \mathrm{mgml}^{-1}$ and $1.9 \pm 0.6 \mathrm{mgml}^{-1}$, respectively. The treated houseflies frequently rubbed their body and became inactive (unable to fly) $1 \mathrm{~h}$ after treatment in both mode of application. Following a $2 \mathrm{~h}$ exposure, the treated flies completely stopped feeding. From the results, it can be perceived that irrespective of the mode of application, ASF influences the physiology of the flies equally. From the behavioural changes observed in treated flies, it was presumed that ASF targets on sites of energy production.

Major mitochondrial enzymes regulating energy production were subjected to inhibition activity assay. A dose-dependent inhibition of SDH and MDH by ASF is shown in Figures 2 and 3 respectively. The inhibitory effect of ASF was found to be less on malate dehydrogenase $(\mathrm{MDH})\left(\mathrm{IC}_{50}=0.72 \mu \mathrm{g} \mathrm{ml}^{-1}, \mathrm{R}^{2}=0.9924 ; \mathrm{P}<0.0001\right)$ than that on succinate dehydrogenase (SDH) $\left(\mathrm{IC}_{50}=0.65 \mu \mathrm{g} \mathrm{ml}^{-1}, \mathrm{R}^{2}=0.9817 ; \mathrm{P}<0.0001\right)$.

Figure 4 shows the amount of ATP present in the whole fly following $24 \mathrm{~h}$ exposure to ASF by oral and contact applications. Total ATP

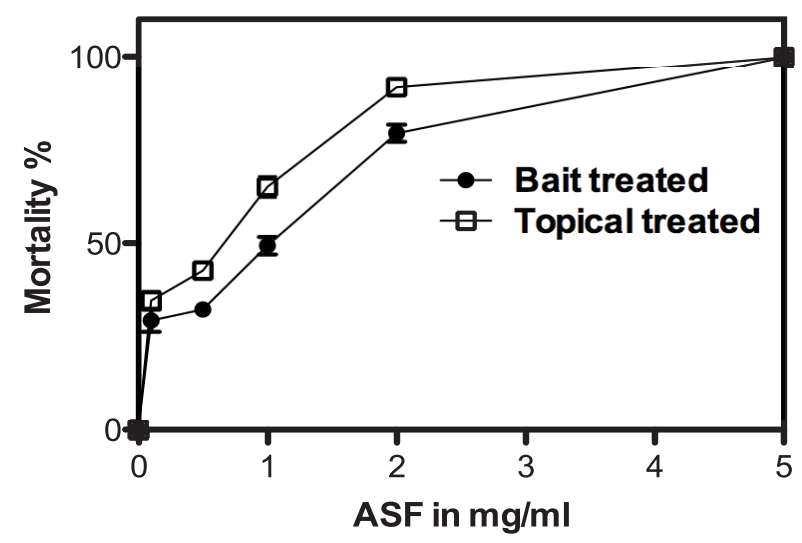

Figure 1: Effect of ASF to $M$. domastica treated with two different kind of formulation (as Bait and Topical treatment). 


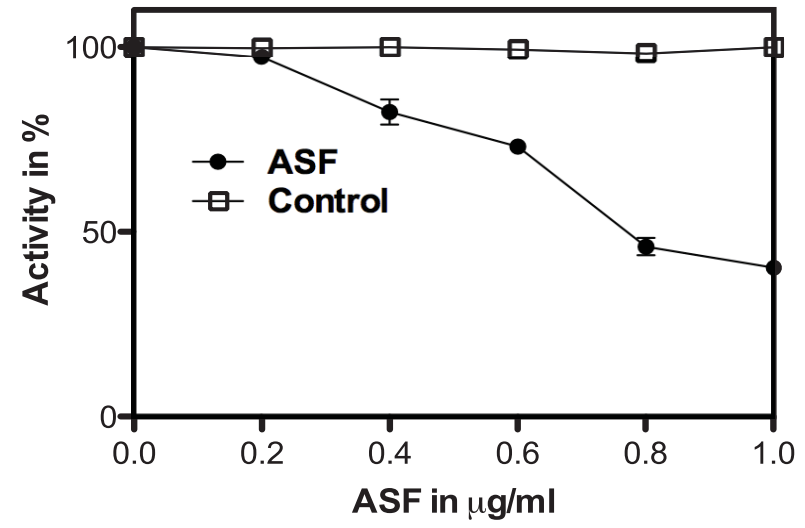

Figure 2: Effect of ASF on the succinate dehydrogenase of $M$. domastica mitochondria.

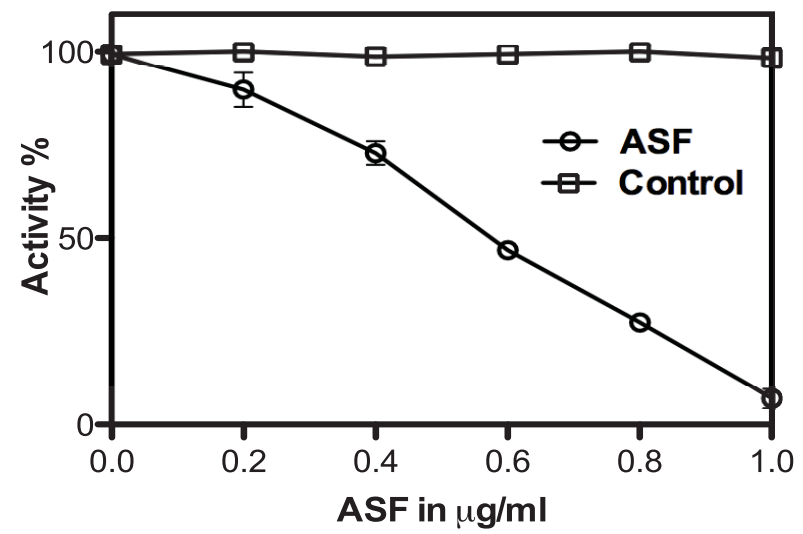

Figure 3: Effect of ASF on the malate dehydrogenase of $M$. domastica mitochondria

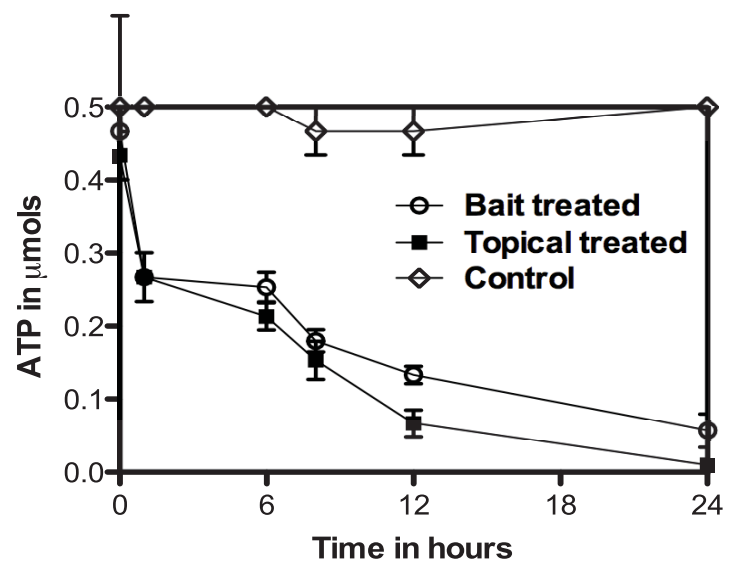

Figure 4: Effect of two different treatments on ATP production by $M$. domastica.

content decreased to $0.075 \mu \mathrm{mols}$ in flies treated with oral formulation $\left(\mathrm{R}^{2}=0.6497 ; \mathrm{P}<0.0001\right)$ and $0.020 \mu \mathrm{mols}$ in flies treated with contact formulation $\left(\mathrm{R}^{2}=0.7513\right.$; $\left.\mathrm{P}<0.0001\right)$ from the initial concentration of $0.45 \mu \mathrm{mols}$ for topical treated and $0.47 \mu \mathrm{mols}$ in the case of bait treated flies, respectively. However, the ATP concentration remained same as initial level (i.e. $0.45-0.50 \mu \mathrm{mols}$ ) in control flies. From the above

\begin{tabular}{|c|c|c|c|}
\hline SI.No. & CAS.No. & Compounds & $\mathrm{mg} \mathrm{g}^{-1}$ \\
\hline 1 & $6871-44-9$ & Diatine & 3.82 \\
\hline 2 & $465-11-2$ & Gamabufagin & 2.68 \\
\hline 3 & $547-98-8$ & Cholestanoic acid & 2.06 \\
\hline 4 & $35536-76-6$ & Corchoroside B & 1.67 \\
\hline 5 & $6625-20-3$ & $\begin{array}{l}\text { Sanchycline } \\
\text { hydrochloride }\end{array}$ & 1.73 \\
\hline 6 & $76-25-5$ & Coupe-A & 1.72 \\
\hline 7 & $509-60-4$ & Paramorfan & 1.99 \\
\hline 8 & $87-44-5$ & Beta-caryophyllene & 25.22 \\
\hline 9 & $1080-26-0$ & Ethyl arachidonate & 3.43 \\
\hline 10 & $96-76-4$ & 2,4-di-t-Butylphenol & 5.04 \\
\hline 11 & $112-39-0$ & Methyl palmitate & 31.41 \\
\hline 12 & $507-79-9$ & Ungernin & 19.82 \\
\hline 13 & $628-97-7$ & Ethyl palmitate & 68.46 \\
\hline 14 & $20987-26-2$ & Resibufaginol & 1.55 \\
\hline 15 & $2777-58-4$ & Methyl petroselinate & 54.15 \\
\hline 6 & $112-61-8$ & Methyl stearate & 16.02 \\
\hline 17 & $111-62-6$ & Oleic acid, ethyl ester & 197.59 \\
\hline 18 & $111-61-5$ & Ethyl stearate & 27.96 \\
\hline 19 & $128-13-2$ & Ursodiol & 1.52 \\
\hline 20 & $27554-26-3$ & Iso-octyl-phthalate & 532.09 \\
\hline
\end{tabular}

Table 1: GC-MS analysis of the acetone-soluble fraction (ASF) of ethanol extract of $A$. squamosa.

data it is evident that ASF interrupts ATP production by inhibition of mitochondrial enzymes. The behavioural observation correlated with these findings. GC-MS analysis of ASF (Table 1) revealed two major compounds, ethyl ester of oleic acid (ethyl oleate) and Iso-octyl phthalate, but previous studies on A. squamosa seeds have reported acetogenins as the active compound [11,15,26-30]. The current study shows the inhibitory activity of ASF on MDH and SDH (Complex II) in housefly, $M$. domestica. The GC-MS analysis proved that ASF contained no trace of acetogenins. Studies regarding the activity of the major compounds are planned to be carried out in our laboratory.

\section{References}

1. Dos Santos AF, Sant'ana AE (2001) Molluscidal properties of some species of Annona. Phytomedicine 8: 115-120.

2. Pavela $R$ (2007) Lethal and sublethal effects of thyme oil (Thymus vulgaris L.) on the House fly (Musca domestica Lin.). Journal of Essential Oil Bearing Plants 10: 346-356.

3. Tarelli G, Zerba EN, Alzogaray RA (2009) Toxicity to vapor exposure and topical application of essential oils and monoterpenes on Musca domestica (Diptera: Muscidae). J Econ Entomol 102: 1383-1388.

4. Pohlit AM, Rezende AR, Lopes Baldin EL, Lopes NP, Neto VF (2011) Plant extracts, isolated phytochemicals and plant-derived agents which are lethal to arthropod vectors of human tropical diseases - a review. Planta Medica 77 618-630.

5. Moeschler HF, Pfluger W, Wendisch D (1987) Pure annonin and a process for the preparation thereof, US Patent 4689232.

6. Mikolajczak KJ, McLaughlin JL, Rupprecht JK (1988) Control of pests with annonaceous acetogenins, US Patent 4721727.

7. Mikolajczak KJ, McLaughlin JL, Rupprecht JK (1989) Control of pests with annonaceous acetogenins, US Patent 4721727

8. Teresa G, Raul A, Jose RT, Amparo MB, Carmen ZMP (1998) Acetogenins from Annona glabra seeds, Phytochemistry 47: 811-816.

9. Mehra BK, Hiradhar PK (2000) Effect of crude acetone extract of seeds of Annona squamosa Linn (Family: Annonaceae) on possible control potential against larvae of Culex quinquefasciatus say. J Entomol Res 24: 141-146.

10. George S, Vincent S (2005) Comparative efficacy of Annona squamosa Linn. and Pongamia glabra Vent. to Azadirachta indica A. juss against mosquitoes. J Vector Borne Dis 42: 159-163. 
Citation: Kempraj V, Bhat SK (2014) Acetone Fraction of Annona squamosa Seed Extract Inhibits Mitochondrial Complex II of Musca domestica. Nat Prod Chem Res 2: 155. doi:10.4172/2329-6836.1000155

11. González-Coloma A, Guadaño A, de Inés C, Martínez-Díaz R, Cortes D (2002) Selective action of acetogenin mitochondrial complex I inhibitors. Z Naturforsch C 57: 1028-1034.

12. Coelho MB, Marangoni S, Macedo ML (2007) Insecticidal action of Annona coriacea lectin against the flour moth Anagasta kuehniella and the rice moth Corcyra cephalonica (Lepidoptera: Pyralidae). Comp Biochem Physiol C Toxicol Pharmacol 146: 406-414.

13. Kempraj V, Bhat KS (2011) Acute and reproductive toxicity of Annona squamosa to Aedes albopictus. Pesticide Biochemistry and Physiology 100: 82-86.

14. Anderson JR, Poorbaugh JH (1964) Observations on the ethology and ecology of various Diptera associated with northern California poultry ranches. Journal of Medical Entomology 1: 131-147.

15. Guadaño A, Gutiérrez C, de La Peña E, Cortes D, González-Coloma A (2000) Insecticidal and mutagenic evaluation of two annonaceous acetogenins. J Nat Prod 63: 773-776.

16. Tan SW, Yap KL, Lee HL (1997) Mechanical transport of rotavirus by the legs and wings of Musca domestica (Diptera: Muscidae). J Med Entomol 34: 527-531.

17. Crosskey RW, Lane RP (1993) Medical Insects and Arachnids. Medical and Veterinary Entomology 8: 178.

18. Howard J (2001) Nuisance flies around a landfill: patterns of abundance and distribution. Waste Manag Res 19: 308-313.

19. Abbott WS (1925) A method for computing the effectiveness of an insecticide. Journal of Economic Entomology 18: 265-267.

20. Finney DJ (1971) Probit Analysis. Cambridge, UK: Cambridge University Press.

21. Knecht W, Altekruse D, Rotgeri A, Gonski S, Löffler M (1997) Rat Dihydroorotate
Dehydrogenase: Isolation of the recombinant enzyme from mitochondria of insect cells. Protein Exp Purif 10: 89-99.

22. Lowry OH, Rosebrough NJ, Farr AL, Randall RJ (1951) Protein measurement with the Folin phenol reagent. J Biol Chem 193: 265-275.

23. Singer TP (1974) Determination of the activity of succinate, NADH, choline and alpha-glycerophosphate dehydrogenases. Methods Biochem Anal 22: 123-175.

24. Yang NC, Ho WM, Chen YH, Hu ML (2002) A convenient one-step extraction of cellular ATP using boiling water for the luciferin-luciferase assay of ATP. Anal Biochem 306: 323-327.

25. Lamprecht W, Trautschold I (1974) Methods of Enzymatic Analysis. Weinheim Germany, Verlag Chemie.

26. Zafra-Polo MC, González MC, Estornell E, Sahpaz S, Cortes D (1996) Acetogenins from Annonaceae, inhibitors of mitochondrial complex I. Phytochemistry 42: 253-271.

27. Byun HO, Kim HY, Lim JJ, Seo YH, Yoon G (2008) Mitochondrial dysfunction by complex II inhibition delays overall cell cycle progression via reactive oxygen species production. J Cell Biochem 104: 1747-1759.

28. Greenberg B (1973) Flics and disease Vol. II. II. Biology and disease transmission. Flics and disease. Vol. II. II. Biology and disease transmission $1-447$.

29. Kazuyoshi K, Jocelyn PA, Kobayashi A (1989) Isolation, Structure of Neoannonin, A novel insecticidal compound from the seeds of Annona squamosa, Agric Biol Chem 53: 2719-2722.

30. Richter C, Park JW, Ames BN (1988) Normal oxidative damage to mitochondrial and nuclear DNA is extensive. Proc Natl Acad Sci U S A 85: 6465-6467. 